\title{
Elecciones y vida política en España entre 1902-1923: persistencias y cambios
}

\author{
Alicia YANINI
}

Es bastante frecuente que los escritos de historia política mantengan cierta ambigüedad en torno a la delimitación del contenido del tema a investigar. El objeto de estudio queda en tal caso indefinido, y aparece arropado por multitud de temas colaterales a la investigación propiamente dicha. Se diría que con esa mezcolanza de temas diferentes, se quisiera conseguir de un público hipotético el reconocimiento de la relevancia explicativa de la investigación realizada. Sin embargo, cabría preguntarse si el efecto que deriva de este "credo metodológico" no resulta más bien contraproducente. Es más, denota una timidez intelectual que suele ir unida a una incapacidad para configurar un esquema interpretativo claro y coherente.

Un buen ejemplo de lo dicho lo tenemos en muchos de los estudios de historia electoral que hasta la fecha se han realizado en España. Esto viene sucediendo porque muchos historiadores, especialmente los que participan -o creen participar - de la metodología marxista, se niegan a analizar lo político como un objeto de investigación con entidad propia. No se acepta que la esfera de lo político pueda tener sus propias leyes de funcionamiento ${ }^{1}$.

Asi, a título de ejemplo, muchos estudios sobre elecciones en la España de la Restauración dedican un tercio del trabajo a confeccionar una estructura socioprofesional al objeto de sentar las bases socioeconómicas que expliquen el comportamiento electoral. Es habitual que tal objetivo

Esa manera de entender la historia política explica muchas de las críticas que han recibido los trabajos de VARELA ORTEGA, especialmente "El proteccionismo de los trigueros castellanos", Cuadernos de Información Comercial Española, n. ${ }^{\circ} 6,1978$, págs. 7-60. 
no se consiga. Otras veces se dedica gran esfuerzo a descubrir los vínculos de los caciques con la agricultura, el comercio, la industria y la especulación financiera, consiguiendo quizá las características económicas de la élite regional, pero sin ampliar nuestro conocimiento de los motivos por los que la conducta electoral de una región determinada no se diferencia, en lo esencial, de la conducta electoral de otra región española con características socioeconómicas bien distintas. El corolario de este tipo de investigaciones es que se ha llegado incluso a afirmar -explícita o implícitamente-que no se puede deslindar, en sentido estricto, lo político de lo económico y social. De tal modo está todo entrelazado. No obstante, el esfuerzo en analizar lo político, separándolo de lo económico y lo social, lo cual no significa ignorar las interacciones que haya entre el todo y las partes, puede ayudarnos a obtener mejores resultados en el análisis de «las elecciones y la vida política» durante la Restauración.

Sin negar que los estudios electorales tienen gran interés en sí mismos para conocer la realidad política de un país o de una región geográfica concreta, quiero señalar que se olvidan a menudo de aquellos grupos políticos que no tienen representación parlamentaria, ni siquiera quizá relevancia electoral, pero que sin duda influyen en la vida política y, a la postre, indirectamente tienen cierta incidencia en el comportamiento electoral de los partidos políticos y los electores. Así, los movimientos huelguísticos, pongo por ejemplo, son significativos del tipo de entorno político en el que se desarrollan unas elecciones. Si hacemos abstracción de dicho entorno y nos fijamos tan sólo en la realidad electoral, tal vez tengamos que concluir que es cierta la afirmación tan difundida de que «el caciquismo dominó la vida política española en el período 1902-1923". Estas afirmaciones de tipo general, aunque ciertas y necesarias, no siempre son suficientes para ampliar la comprensión de una realidad que, con otro enfoque distinto, se nos puede mostrar más accesible. Hay ciudades en España donde, a principios del siglo xx, los movimientos huelguísticos eran inexistentes, mientras que en otras, como en Barcelona, tenían una influencia notable en el conjunto de la vida política en general y en las elecciones en particular, ya en $1902^{2}$.

De lo dicho se deduce que el estudio de las elecciones precisa ir acompañado de un conocimiento, previo o simultáneo, de la vida política. Ello nos permitiría ir más allá de lo meramente descriptivo y nos introduciría en un mundo más complejo. De ese modo se evitaría que, tras

2 Riouer, Borja de, Lliga regionalista: la burguesia catalana i el nacionalisme (1898-1904). Barcelona, Edicions 62 ,1977, pág. 233. 
una pormenorizada descripción de las elecciones y el comportamiento caciquil en una región, provincia, comarca o distrito, tan sólo se llegara a conclusiones ya formuladas con anterioridad por otros estudiosos del tema.

No aportan nada nuevo que no sea una cantidad de votos configurando una elección manipulada con unos métodos más o menos variopintos. No obstante, estas investigaciones, portadoras de gran acopio de datos, tienen un valor documental nada despreciable y ha llegado el momento de utilizarlas con la finalidad de elaborar conocimientos más interpretativos acerca de la evolución de ese sistema político en el largo período que va de 1876 a 1923. Asimismo, podríamos llegar a conocer cuáles fueron las consecuencias, pretéritas y actuales, de que España estuviera dominada por el caciquismo durante tan largo período de tiempo, y de qué modo la particular evolución del sistema político y del comportamiento electoral influyó en la decisión de adoptar una solución autoritaria a la crisis del sistema.

En una investigación realizada en la provincia de Valencia $^{3}$ sostuve que, a lo largo del período 1876-1901, se observaba una evolución en las estructuras políticas de la provincia, evolución que, en medio del atraso, permitía hablar de cierta modernización en el comportamiento político. Todo esto quedaba demostrado a partir del análisis de las campañas electorales, la forma en que se escribían los manifiestos electorales, así como el contenido de los mismos y la manera en que actuaban los intermediarios entre el mundo rural y las instituciones del Estado liberal. Sin embargo, no es mi intención negar que el campo valenciano, y hasta 1890 también la ciudad, estaban controlados por los caciques y su actuación e influencia en las elecciones y en la vida pública era lo habitual $y$ predominante.

Esta última matización no lleva necesariamente a aceptar sin objeción las afirmaciones de quienes aseguran que las estructuras políticas no se modernizaron con mayor celeridad, a lo largo del siglo $x \mid x$, ni siquiera allí donde existía un fuerte desarrollo industrial ${ }^{4}$. Otros autores defienden que el sufragio universal reinstaurado en 1890 no hizo más que ampliar la esfera de influencia de los caciques, sin que reportara una mejora en las costumbres políticas ni una disminución del fraude electoral y la corrup-

\footnotetext{
3 Yanini A., Elecciones caciquiles en la provincia de Valencia. Política y sociedad entre 1876 y 1901. Tesis doctoral inédita, Universidad de Valencia, 1983.

4 Ranzato, G., La aventura de una ciudad industrial. Sabadell entre el Antiguo Régimen y la modernidad. Barcelona, Península, 1987
} 
ción ${ }^{5}$. Estas tesis han sido corroboradas en las investigaciones realizadas en Cataluña que, comparada con otras regiones españolas, ha sido considerada tradicionalmente como la de mayor desarrollo económico y más amplia socialización política. A pesar de esto último, vemos que la Lliga Regionalista —el primer partido moderno del catalanismo»; ${ }^{6}$ - cuando se extendió de Barcelona, donde tenía su origen, al mundo rural, adquirió unas características diferentes, propias de "la vieja política». Los campesinos votaban ayudando a los propietarios en su política catalanista y el caciquismo siguió siendo la forma de comportamiento político predominante hasta $1923^{7}$. Algunos estudios van más allá en las fechas y afirman que incluso en 1931 se constata un comportamiento electoral que no dio el paso de lo personal a lo político, aunque hubiera núcleos aislados, interesados en acabar con el amiguismo, el familismo y las lealtades políticas del campesino catalán ${ }^{8}$.

Hay cierta unanimidad: en las primeras décadas del siglo $x x$ no se puede hablar de cambios políticos, considerando el sistema globalmente, sino de persistencia del modelo político imperante a lo largo de la segunda mitad del siglo XIX en toda España. Este tipo de afirmaciones, ya lo dijimos anteriormente, aunque puedan ser aceptadas como ciertas, deben matizarse mucho. En efecto, el punto de partida del presente trabajo fue la implícita aceptación de que un estudio electoral nos da una visión muy parcial de las actitudes políticas durante la Restauración. Dado que el análisis electoral pretende conocer más de la vida política, y dado que, al margen del modo en que se desenvuelvan las elecciones, surgen y se desarrollan instituciones y organizaciones que vertebran la vida política de una manera diferente, se hace imprescindible conocer las características de estas instituciones y organizaciones. Una buena manera de aproximarse a este tipo de análisis son las investigaciones por provincias, comarcas y distritos, sin que el estudio electoral pase a ser marginal, sino complementario, y que nos ayude a matizar las grandes afirmaciones sobre el sistema y el modelo político. Todo eso podría demostrarnos que sí hubo cambios relevantes en el sistema, los cuales pueden hacer comprensible la crisis en que se vio sumido en la década de 1920.

5 DARDÉ, C., "La implantación de la democracia en la España de la Restauración", Revista de Occidente, 50, 1985, págs. 114-126.

6 RiQuen, op. cit, pág. 202 y 213.

HANSEN, E. C., "The State and Land Tenure conflicts in rural Catalonia", Anthropological Quarterly, 1969, pág. 230

a MiR Cuncó C., Lleida (1890-1936): caciquisme politic i lluita electoral. Barcelona, Publicacions de l'Abadia de Monserrat, 1985. 
No voy a ejemplificar sobre la provincia de Valencia, que fue el ámbito geográfico en que se desarrolló mi propia investigación ${ }^{9}$, sino sobre $\mathrm{Ca}$ taluña.

Un buen ejemplo se puede entresacar de las actitudes políticas de los "rabassaires" en el Alto Penedés. Sabemos que las elecciones estuvieron bajo el control caciquil de los propietarios de la tierra hasta 1923, ello no impidió que a partir de 1890 fuera acrecentándose el enfrentamiento entre cultivadores directos y propietarios. Empezaron, por tanto, a surgir ligas de campesinos - «unions de rabassaires"- que conviene no ignorar, dado que introdujeron un nuevo elemento de vida política en la comarca. El ejemplo escogido nos muestra que, aunque los propietarios controlaran las "elecciones", no podemos colegir que toda la "vida política" estuviera bajo su dominio. Otro ejemplo posible es el comportamiento político de los campesinos del Camp de Tarragona, comarca catalana en la que el cooperativismo tuvo gran incidencia en la vida política ya desde finales del siglo xix. En definitiva, control electoral no siempre es sinónimo de control político, máxime cuando abunda la abstención. De ahí que, siguiendo con más ejemplos, aunque dos regiones tan dispares como $\mathrm{Ca}$ taluña y Cáceres estuvieran dentro de un mismo sistema político-caciquil, hay que establecer diferencias que maticen una afirmación tan general. No hay duda; el comportamiento político-electoral de Cataluña, a diferencia del de Cáceres, no se caracterizó por la total desmovilización y dependencia ${ }^{10}$.

Podemos avanzar otra conclusión, a saber que los estudios de historia electoral realizados carecen de un análisis comparativo con otras regiones españolas ${ }^{11}$, lo cual impide salir fuera del marco de afirmaciones generales como las que venimos comentando, $y$, al no quedar claramente establecidas las diferencias regionales, no se enriquecen las últimas interpretaciones "globales" dadas acerca de la "naturaleza y evolución del sistema político" de la Restauración ${ }^{12}$. Dichas interpretaciones coinciden en afirmar que amplios sectores de la población optaron por la desmo-

9 YANINI, A., OP. cit.

10 Merinero, M. J., Comportamiento politico en Cáceres (1891-1923). Desmovilización y dependencia. Cáceres, El Brocense, 1981.

'Uno de los primeros análisis comparativos en que explícitamente se propuso "estudiar hasta qué punto el sistema caciquil andaluz era idéritico al del resto de España" fue realizado por TUSELL, J., "El sistema caciquil andaluz comparado con otras regiones españolas (19031923)", Revista Española de Investigaciones Sociologicas, n. ${ }^{\circ} 2,1978$, pág. $7-19$

TUSELL, J., Oligarquía y caciquismo en Andalucia (1890-1923). Barcelona, Planeta, 1976. Varela Ortega, J., Los amigos políticos. Elecciones, partidos y caciquismo en la Restauración (1875-1900). Madrid, Alianza, 1977. 
vilización y el apoliticismo; el sistema liberal decimonónico tan sólo pretendía la participación político-electoral de la élite. Con el transcurrir del tiempo, en el primer tercio del siglo xx, cuando las masas abstenidas de la política decidieron participar, el sistema caciquil entró en crisis.

No obstante lo indubitable de tales afirmaciones, cuando se pretende "caracterizar dicha crisis» o si se pretende conocer los “límites cronológicos y regionales", entonces empiezan a surgir dudas. Hasta ahora se ha prestado mayor atención a las "persistencias" que a los "cambios" que se operan en las elecciones y la vida política. Ello ha conducido a que conozcamos mejor la "naturaleza" de las elecciones, y al Régimen que las patrocinaba, que no su "evolución".

Tenemos un hecho indiscutible: el 13 de septiembre de 1923 un régimen autoritario asumió el poder en España. Lo mismo sucedió en otros países europeos en la década de los veinte y treinta. En todos los casos se había aceptado la doctrina liberal, produciéndose posteriormente una "ruptura con el liberalismo y el parlamentarismo", al objeto de evitar la democratización del sistema político. En otros Estados no se produjo tal ruptura y la "transición del liberalismo oligárquico al democrático" se produjo de manera paulatina y pacífica. Cabe preguntarse cuáles fueron las razones, "de carácter político» ${ }^{13}$ que impidieron la transición paulatina hacia la democracia en España y favorecieron la solución autoritaria de Primo de Rivera. El debate historiográfico sobre el tema ha sido acertadamente planteado en torno a los límites del régimen: la Corona y su papel arbitral, los partidos dinásticos y su falta de reformismo político, el Ejército y su pretorianismo. Ahora bien, dados los objetivos que se persiguen en el presente trabajo, habría que preguntarse cuál fue la actitud política de las diversas élites regionales, ya estuvieran en armonia o en abierta oposición al "turno" electoral y parlamentario, y también cabe preguntarse de qué modo y en qué regiones los conatos de resistencia al

13 Una vez más se me impone la necesidad de enfatizar la conveniencia de buscar las razones en los mecanismos políticos y huir de explicaciones económicas fáciles. Es cierto que en los países más industrializados de Europa se optó por una solución de "transición» (Gran Bretaña, Suecia..., ). También lo es que en Estados con un alto grado de desarrollo industrial (Alemania, Italia...) se optó por la "ruptura» con el parlamentarismo liberal. En esta misma línea de razonamiento no me parece aceptable la afirmación, a modo de conclusión, de Ranzato: «ll corretto funzionamento del sistema liberal --democratico sarebbe un lusso dei paesi sviluppati e prosperi, mentre la sua degenerazione e corruzione sono inevitabili attributi dei paesi arretrati e poveri". En todo caso, sería aceptable como descripción, no como explicación del porqué las cosas han sucedido de ese modo. En: "Natura e funzionamento di un sistema pseudo-rappresentativo: la Spagna "liberal-democratica" (1875-1923)". Annali della fondazione Lelio e Lisle Basso-Issoco, 1989, vol. IX, pág. 253 
sistema de la Restauración cristalizaron en núcleos de vida política democrática.

No todos los historiadores estarían de acuerdo en aceptar que en la década de los veinte los mecanismos de funcionamiento del sistema político español estuvieran experimentando una evolución que apuntara hacia un proceso democratizador. El polémico tema ha sido perfectamente planteado ${ }^{14}$ :

\begin{abstract}
«Existe una opinión, difundida principalmente por historiadores anglosajones, que ha interpretado la Dictadura primorriverista como el régimen que vino a cortar por lo sano los intentos democratizadores que se dieron en el último año de funcionamiento del sistema de la Restauración. Esta opinión comenzó con Salvador de Madariaga cuando afirmó: "no pereció, pues, el antiguo régimen por corrupción, sino por haber dado síntomas de irse curando de su corrupción" y fue corroborada por Raymond Carr al afirmar: "no era la primera, ni la última vez, que un general aseguraba rematar un cuerpo enfermo cuando, de hecho, estaba estrangulando a un recién nacido". Más recientemente Shlomo Ben -Ami insistía: "el golpe de Estado no se dio simplemente para expulsar del poder a los viejos partidos políticos, sino para cortar de raíz un proceso prometedor para la democracia"'".
\end{abstract}

Sin embargo, en líneas generales, los estudios sobre elecciones aseguran, implícitamente en muchos casos, que no asistimos a un proceso de crecimiento de la democracia, sino que el "turno", asentado sobre el caciquismo, permaneció a pesar de la implantación del sufragio universal. Por lo tanto, de acuerdo con estas tesis, la crisis del sistema no se debió a que la oposición lograra sacar a abstencionistas de su letargo, sino que fueron los propios partidos del "turno" quienes propiciaron la crisis del sistema, dada la incapacidad para llegar a acuerdos y pactos en el interior de la élite ${ }^{15}$.

14 González Calbet, T., “La destrucción del sistema político de la Restauración: el golpe de septiembre de 1923", en: J. L. García Delgado (ed.), La crisis de la Restauración. España, entre la Primera Guerra Mundial y la II República. Madrid, Siglo xxl, 1986. Véase de la misma autora, La dictadura de Primo de Rivera. El directorio militar. Madrid, El Arquero, 1987, pág. 110.

15 No son pocos quienes suscribirian tal afirmación. Como una pequeña muestra me remito a las obras ya citadas, véanse notas $4,5,8$ y 10 . Asimismo, para seguir ejemplificando con Cataluña, se puede consultar la obra de Balcells, A., CULLA, J. B., y MIR, C., Les eleccions generals a Catalunya de 1901 a 1923. Fundació Jaume Bofill, Barcelona, 1982, pág. 13 ("perqué el restabliment del sufragi universal no suposà uncanvi real en el comportament electoral modern a partir només de 1931 ), pág. 21 ("Resultava inviable intentar convertir les clienteles sumises en partits moderns d'afiliats») 
Había, ciertamente, una falta de acuerdo no sólo en el Parlamento, sino en los momentos previos a la contienda electoral, cuando tenía que elaborarse el pacto del "encasillado". Me permito sugerir si una de las razones de que cambiaran las relaciones en el interior de la élite no sería que las minorías del «turno» estaban claramente amenazadas por las minorias contrarias al "turnismo»: tradicionalistas (integristas y carlistas), republicanos, socialistas, regionalistas y nacionalistas; fuerzas políticas que tuvieron relevancia en el País Vasco ${ }^{16}$. Cataluña ${ }^{17}$ y País Valenciano ${ }^{18}$, así como en las grandes ciudades de Madrid, Barcelona, Valencia y Bilbao ${ }^{19}$. Es de aceptación común, incluso entre autores reacios a aceptar que hubiera novedades relevantes en el sistema político y su funcionamiento, que los Gobiernos fueron inestables por falta de mayorías parlamentarias, pero quizá habría que fijar más la atención en lo que estaba sucediendo fuera del Parlamento. Si así se hace, el comportamiento electoral, y político en general, de determinadas regiones y ciudades me lleva a afirmar que los ideales democráticos, y los intentos de ponerlos en práctica a través de las elecciones y la sociabilidad democrática, propiciaron grandes cambios en el período aquí analizado. Ello no es contrario a la afirmación de que la mayor parte del país fuera todavía ajena a los valores de la democracia, lo cual queda perfectamente expresado en el texto de Ronald Fraser que introduce uno de los capítulos del libro de Shlomo Ben-Ami ${ }^{20}$ :

"Las clases gobernantes concedian el sufragio universal en la medida en que podian manipularlo. Poco a poco, la gente comenzó a despertar, empezamos a saber que existía una nación llamada Francia; empezamos

10 Castels, L., Modernización y dinámica politica en la sociedad guipuzcoana de la Restauración, 1876-1915. Madrid, Siglo xxı, 1887, págs. 271-343. Fusı, J. P., El País Vasco. Pluralismo y nacionalidad. Madrid, Alianza, 1984, págs. 45-47, 150 y sigs.

17 Bacells, A., Culla, J. B., MiR, C., op. cit, pág. 23. Una vez más apuntan la esterilidad de las victorias electorales de los autonomistas de derecha y de izquierda y de los republicanos. Los "turnistas", según afirman los autores del libro, perdían terreno en Cataluña, pero las "oposiciones turnistas", no sacaban fruto alguno dado que los partidos dinásticos controlaban la mayor parte de España. Considero que esa última apreciación debería ser objeto de estudio y discusión científica. De hecho, las minorías políticas pueden tardar varios años en recoger frutos, sin que necesariamente su actividad en la vida política deba ser tachada de estéril.

is AgulLó Lucia, L., Sociologia electoral valenciana (1903-1923). Las elecciones en Valencia durante el reinado de Alfonso XIII. Universidad de Valencia (Cátedra Fadrique Furió), 1976.

19 Martinez Cuadrado, M., Elecciones y partidos políticos en España (1868-1931). Madrid, Taurus, 1969 , vol. II, págs. 693, 700 y 863 .

20 Juan Moreno, zapatero de un pueblo andaluz, de 74 años (en 1973). En Ronald Frasef, El pueblo. A Mountain Village on the Costa del Sol, a través de ShLOMO BeN-Ami, La dictadura de Primo de Rivera, 1923-1930. Barcelona, Planeta, 1984, pág. 25. 
a leer y a aprender algo. Pero de una manera extraña, sin escuelas ni educación, de modo que sólo podíamos adivinar el valor del voto. Cuando lo descubrimos nos lo quitaron y trajeron la dictadura de Primo de Rivera, que duró siete años».

En la historiografía española más reciente, a partir de los últimos años de la década de los setenta del presente siglo, parece un lugar común la afirmación de que el sufragio universal de 1890 sólo consiguió una ampliación de las clientelas caciquiles y no una democratización del régimen oligárquico. Si nos remontamos una década en los escritos de historia electoral nos encontramos con un libro de lectura obligada para quien quiera adentrarse en el análisis de las elecciones durante la Restauración. El autor del libro al que hacemos referencia, Martínez Cuadrado ${ }^{21}$ disiente de quienes dan por hecho que el sufragio universal amplió el sistema caciquil. Por el contrario, encuentra en la ley del sufragio universal de 1890 y en la ley de asociaciones de 1888 un camino abierto al triunfo del republicanismo en las ciudades más importantes de España.

Las razones en las que se apoya son totalmente empíricas, es decir, la cuantificación del número de votos y de escaños conseguidos por el republicanismo en las elecciones legislativas. Si esto mismo lo observamos desde otro ángulo, para no limitarnos a los partidos republicanos, y lo hacemos extensivo a lo que consideramos otros exponentes de la fuerza motriz del cambio electoral y político, vemos que la consecución de escaños por parte de las minorías no "turnistas" era el inicio del fracaso del "turno", que no pudo imponer a sus candidatos al fallar su "máquina electoral», engranaje esencial para el correcto funcionamiento del Régimen.

Podemos preguntarnos si estos hechos, más o menos aislados, pero perfectamente cuantificados, se pueden considerar un indicador de las transformaciones que se estaban operando en las elecciones y en la vida parlamentaria, o si son datos cuantitativamente irrelevantes.

En cualquier caso aunque este triunfo de las minorías de oposición al "turno" no signifique subvertir el funcionamiento del sistema, podemos lícitamente preguntarnos si en las grandes ciudades españolas había una vida política que representaba una barrera a superar por los partidos dinásticos. $Y$ si es así, como efectivamente lo fue, interesaría profundizar en el análisis de esos impedimentos que dificultaron el fluido funciona-

21 Martínez Cuadrado, op. cit., tomo II, págs. 689, 692, 693, 698 y 863. 
miento de la "máquina electoral" en las ciudades, y que no existieron en igual medida en el mundo rural.

Es más, esos impedimentos con que tropezó el engranaje de la «máquina electoral", ¿por qué no calificarlos de modernizadores - democratizadores- de la estructura política que venía apoyando al régimen creado en 1875 ?

En resumidas cuentas, si bien es cierto que en investigación la conclusión general a que se llega puede invalidar conclusiones parciales, que disienten de la tesis central, también es cierto que, según mi punto de vista, no nos hallamos ante semejante caso, porque el estudio de los cambios parciales que se van operando en el devenir político español a lo largo de dos décadas (1902-1923) son explicativos de lo que electoralmente sucedería en 1931.

Hemos visto que surgieron agrupaciones políticamente reformistas, contrarias al Régimen. En muchas ciudades, las masas, agrupadas en torno a partidos políticos modernos, abandonaron la abstención y lograron que los tradicionales manejos electorales fracasaran. También encontramos intentos similares en algunos distritos rurales. La abstención electoral empezó a tener un significado ambivalente. Ya no se trataba tan sólo de ingnorancia del valor del voto, sino de núcleos de resistencia política, que podían asimismo ser de distinto signo político: liberal, conservador, republicano...

Todo lo dicho nos lleva a afirmar que el estudio de las elecciones y la vida política muestra ese deseo de cambio. Ahora bien, su expresión era todavía marginal, pero no por esto puede ser tachado de irrelevante. El estudio de los cambios políticos, estableciendo diferencias comparativas entre las distintas regiones españolas, constituye una vía de acceso a datos sumamente prometedores. 


\title{
Vida política y elecciones: Persistencias y cambios
}

\author{
Carlos dardé
}

El objeto de la presente intervención es el análisis de los problemas fundamentales relativos al comportamiento político de la mayor parte de la población, especialmente el que se manifestó en las elecciones, durante el reinado de Alfonso XIII. (En este análisis prescindiré por completo de la situación específica de Cataluña y el País Valenciano, que serán tratados en la intervención de Alicia Yanini.) En primer lugar, expondré las conclusiones básicas que se deducen de la historiografía sobre el tema publicado en los últimos veinte años, aproximadamente, para centrarme después en los problemas de interpretación relativos al caciquismo, el fenómeno más importante de la vida política en España durante este período ${ }^{1}$.

Aunque enfocado sobre el conjunto de la población, este análisis resulta pertinente en un coloquio sobre elites porque, desde otra perspectiva, uno de los problemas fundamentales que se plantea es el de la naturaleza y evolución del poder político de las elites locales.

\section{CONCLUSIONES DE LA HISTORIOGRAFIA}

1. Las persistencias. Sigue predominando en la historiografia la idea tradicional de que, en lo que se refiere a la vida política durante el reinado

En la información y reflexión sobre estos temas, me he beneficiado en gran medida de las actividades llevadas a cabo, desde 1985, por el grupo de trabajo sobre vida política de la Restauración, de la Fundación Ortega y Gasset, dirigido por José Varela Ortega, del que formo parte. Una beca del Ministerio de Educación y Ciencia me ha permitido pasar seis meses de 1989 en St. Antony's College, de la Universidad de Oxford donde, además de contar con un ambiente estimulante, he podido consultar buena parte de la bibliografía utilizada en esta ponencia. 
de Alfonso XIII, las persistencias fueron mucho más importantes que los cambios. Globalmente, el comportamiento político en España no experimentó un cambio sustancial, respecto al existente en las primeras décadas de la Restauración. No llegó a ser un comportamiento libre y consciente, de acuerdo con la percepción individual de los intereses personales o colectivos, o con valores asumidos personalmente, sino que siguió estando dominado por lo que genéricamente llamamos caciquismo.

El indicador que parece irrefutable en este sentido es el hecho de que los partidos conservador y liberal, cuando fueron llamados al gobierno por la Corona, siguieron obteniendo, alternativamente, cómodas mayorías electorales, que no eran reflejo, en absoluto, de cambios paralelos en la opinión. El fracaso del gobierno Maura en las elecciones de 1919, aunque significativo de las limitaciones del poder electoral del ministro de la Gobernación en las postrimerías del sistema, fue consecuencia exclusiva de la división de los conservadores y de la falta de organización suficiente por parte de los mauristas, no de un cambio en el comportamiento político del país, como las siguientes victorias electorales de conservadores y liberales, en 1920 y 1923, respectivamente, se encargarían de demostrar.

El consenso en este punto es prácticamente unánime. Los diversos estudios regionales publicados referentes a Andalucía, Aragón, Asturias, Canarias, Cantabria, Castilla-León, Castilla-La Mancha, Extremadura, y Galicia, llegan a la misma conclusión - la persistencia en 1923 de lo fundamental del sistema-, en el área de sus respectivos trabajos. Incluso quienes, como $R$. Carr, afirman que el régimen estaba empezando a regenerarse cuando se produjo el golpe de Estado de Primo de Rivera, lo hacen basándose, sobre todo, en la actuación más crítica e independiente del Parlamento - según se manifestó en el tema de las responsabilidades militares en Marruecos- $y$ en los principios que animaban a la nueva concentración liberal. Sólo S. Ben-Ami hace referencia incidentalmente a un electorado «mucho menos manipulable que en el pasado (...) cada vez más independiente", pero la única prueba que aporta para justificar su afirmación es la disminución de la influencia electoral del ministro de la Gobernación; sin embargo, como sabemos, y trataremos de ello más adelante, esto era perfectamente compatible con el sistema de oligarquía y caciquismo, con la existencia de otras influencias independientes del Ministerio o de los gobiernos civiles ${ }^{2}$.

2 TUSELL, J., Oligarquia y caciquismo en Andalucia, 1890-1923. Barcelona 1976. TUSELL, J., "El sistema caciquil andaluz comparado con otras regiones españolas", Revista Española de Investigaciones Sociológicas (1978), 7-19. Frías Corredor, C. Y Trisán Casals, M., El caciquismo altoaragonés durante la Restauración. Huesca 1987. Giron, J., "Elecciones municipales 
No obstante, los distritos caciquilies no permanecieron inmutables. Experimentaron cambios que, sin alterar su caracterización básica, supusieron una variaciación en dos aspectos importantes: la relación entre poder central y elites locales, por una parte, y la relación entre elites políticas y económicas, a nivel local, por otra. Aspectos que constituyen elementos centrales en la interpretación del caciquismo.

Respecto a lo primero - la relación entre poder central y elites locales- las estadísticas globales muestran que las mayorías gubernamentales, sin dejar de ser absolutas, fueron cada vez más pequeñas. Esto era consecuencia, en parte, de la división de los partidos dinásticos y del surgimiento y desarrollo de los partidos nacionalistas, pero, sobre todo, como indican los estudios regionales, de la tendencia a la constitución de lo que J. Tusell ha denominado "cacicatos estables", distritos que permanecian bajo el control de una misma persona, con independencia del partido que estuviera en el poder, lo cual es indicativo, indudablemente, de la consolidación de los poderes locales frente al poder central; las actas de diputados a disposición del gobierno de turno disminuyeron, 10 mismo que la influencia de los gobernadores civiles, al tiempo que aumentaba la de las elites locales, en un cierto proceso de adquisición de autonomía.

Este hecho viene a desmentir la correspondencia entre igualdad y centralización, que afirmaron, y temieron, Burke y Tocqueville. La implantación de la democracia no sólo no supuso, en España, la destrucción de todas las instituciones intermedias entre los individuos y el estado central, sino que, como ha indicado S. Rokkan como tendencia general, reforzó en ocasiones las lealtades hacia los notables locales e impulsó el desarrollo de nuevas organizaciones ${ }^{3}$.

y generales, 1902-1917 ", en Historia General de Asturias, vol. 5, págs, 161-176. GonZALEZ MUNiz, M. A., "Elecciones en el periodo 1918-1923", en Historia General de Asturias, vol. 6, págs. 4964. Noreña Salto, M. T., Canarias: Política y sociedad durante la Restauración. Santa Cruz de Tenerife 1977, 2 vols. Garrido Martin, A., Elecciones y partidos politicos en Cantabria, Memoria de Licenciatura inédita, Universidad de Cantabria, 1986. Romero, C., Soria, 1868-1936 (Aspectos demográficos, socioeconómicos, culturales y politicos).Soria 1981. BARREDA FonTES, J. M., Caciques y electores. Ciudad Real durante la Restauración, 1876-1923. Ciudad Real 1986. CASA NAvaRRo, $F$. de la, La vida política toledana durante el reinado de Alfonso XIII, 1902-1931, tesis doctoral UNED, 1986. MERINERO, M. J., Comportamiento político en Cáceres, 1891-1931. Cáceres 1980. DuRÁN, J. A., Agrarismo y movilización campesina en el país gallego, 1875-1912. Madrid 1977. TABOADA MOURE, P. Las elites y el poder politico. Elecciones provinciales en Pontevedra, 1836-1923. Pontevedra 1987. CARR, R., Spain, 1808-1975. Oxford 1982, págs. 516-523, 2. ed. BEN-AMI, Sh., Fascisme from above. The Dictatorship of Primo de Rivera in Spain, 19231930. Oxford 1983, págs. 22-24.

${ }^{3}$ Cuadrado, M. M., Elecciones y partidos políticos de España, 1868-1931. Madrid 1969, vol. II. ARtola, M., Partidos y programas políticos, 1808-1936. Madrid 1974, vol. I, pág. 128. RokKaN, S., 
Respecto a la segunda cuestión - la relación entre elites políticas y económicas, a nivel local- en algunas regiones, al menos, cabe apreciar una tendencia hacia la profesionalización de la política, a la distinción entre elites económicas y políticas. Así, J. Tusell ha señalado la sustitución, en Andalucía, de los notables locales por políticos profesionales al frente de las instituciones y los partidos. «En 1891 podía todavía resultar (...) que los dos jefes de los partidos del turno fueran, al mismo tiempo, los dos primeros contribuyentes. En 1923, en todas las provincias los jefes de los partidos del turno son políticos profesionales" ${ }^{4}$.

No tenemos conclusiones significativas sobre la evolución de dos aspectos fundamentales del proceso electoral: la participación y la competitividad; en el primer caso, porque no es posible obtenerla dada la falsificación sistemática de los resultados electorales; en el segundo, parece apreciarse un ligero aumento de la competitividad, aunque con grandes variaciones entre unas elecciones y otras. Por otra parte, parece que la violencia física sobre los electores fue disminuyendo al tiempo que aumentaba la importancia de la compra de votos.

2. Los cambios reales. La continuidad global no quiere decir que, en determinados lugares, el electorado no hubiera conseguido, en conjunto, emanciparse del caciquismo. Aunque la movilización política no fuera realmente intensa, sí fue lo suficiente para permitir que se impusiera en ellos la voluntad popular, al menos del pueblo que acudía a votar, lo que en muchos casos significó el triunfo de las corrientes de oposición tanto tradicionales como nuevas. Desde luego, eso ocurrió en la ciudad de Madrid donde, durante todo el período que estamos considerando, no se puede hablar de apatía, fraude, o suplantación sistemática de la voluntad del electorado. Aunque con una participación reducida, entre el 30 y el 40 por 100 -en este caso si pueden darse estadísticas de participación relativamente fiables - la opinión pudo llegar a desempeñar el papel determinante: en seis de las diez elecciones celebradas entre 1903 y 1923, las oposiciones al sistema, republicanos primero y socialistas más tarde, consiguieron la mayoría de las actas; incluso «los partidos dinásticos - ha escrito J. Tusell- podian no tener una estructura moderna, pero tampoco se puede decir que no representaban nada en absoluto"; detrás de ellos estaban diversas asociaciones locales de importancia ${ }^{5}$.

"The comparative study of political participation. Notes toward a perspective on current research", en RANNEY, A. (ed.), Essays on the behavioral study of politics. Urbana 1962, págs. 68-70.

4 TUSELL, J., Oligarquia y caciquismo..., pág. 587.

5 TUSELL, J., Sociología electoral de Madrid, 1903-1931. Madrid 1969. TUSELL, J., «El comportamiento electoral madrileño revisitado", en Bahamonde Magro, A. y Otero CarVajaL, L. E. (eds.), La sociedad madrileña durante la Restauración. Madrid 1989, vol. II, págs. 26-37. 
En Bilbao, como ha indicado J.P. Fusi, los repetidos triunfos de republicanos y socialistas, en elecciones locales y nacionales, a pesar de que necesitaran recurrir frecuentemente a prácticas fraudulentas, como "volcar" el censo de los distritos obreros de la ciudad, indican también el papel determinante de la opinión; por más que Indalecio Prieto, como señala J.P. Fusi, se lamentara de la debilidad de dicha opinión, el comportamiento político de la capital vizcaína estaba en la vanguardia del país ${ }^{6}$.

La movilización no era exclusiva de las grandes ciudades; en todas las demás, como demuestran las estadísticas de las elecciones nacionales cuando se analizan por secciones, y los resultados de las elecciones municipales, había grupos más o menos numerosos, políticamente activos, que participaban libremente. En momentos de extraordinaria agitación política - 1903, 1910 - llegaron a imponerse en las elecciones de diputados, pero el sistema de circunscripciones hacía que sus votos quedaran habitualmente sepultados por los de las secciones rurales, donde predominaba el caciquismo. En ese sentido, como he indicado en otro lugar, la ley electoral de 1890 - no reformada esencialmente por la de 1907que establecía el sufragio universal y la distribución territorial de los escaños, no fue un factor positivo para la evolución del sistema, ni para la modernización política sino, por el contrario, un factor retardatario porque obstaculizó la formación de una opinión pública eficaz, aumentando el poder de los caciques que controlaban a la mayoría rural del país ${ }^{7}$.

En Andalucia, J. Tusell ha señalado la relativa excepción, respecto al sistema de oligarquía y caciquismo, del comportamiento político de dos distritos rurales: Montilla (Córdoba) y Valverde del Camino (Huelva), que denomina semimodernos. En ellos, a pesar de la existencia de coacciones y fraudes, puestos en práctica tanto por los partidos del turno como por las oposiciones, los votos emitidos libremente pudieron llegar a imponerse en algunas ocasiones ${ }^{8}$.

3. Los cambios aparentes. Aquellas localidades donde salían elegidos diputados que tenían una clara significación ideológica contraria al sistema, tanto de la derecha - carlistas, nacionalistas vascos - como de la izquierda - republicanos, socialistas- plantean un problema especial.

${ }^{6}$ Fusı, J. P., Política obrera en el País Vasco, 1880-1923. Madrid 1975, págs. 337-382.

7 DARDE, C., "La implantación de la democracia en la España de la Restauración", Revista de Occidente 50 (1985), 115-126. Sobre la Ley de 1907, TUSELL, J., «Para la sociologia política de la España contemporánea: El impacto de la Ley de 1907 en el comportamiento electoral», Hispania XXX, 116 (1970), 571-631.

${ }_{8}$ TUSELL, J., Oligarquia y caciquismo..., págs. 244-252. 
Estos resultados, ¿eran consecuencia de una movilización real del electorado, de un voto emitido libremente por participar de las mismas ideas del candidato, o se debían a prácticas fraudulentas o a influencias personas? En definitiva, ieran expresión de un cambio auténtico en la naturaleza de la vida política? Es un problema similar al que se ha planteado en relación con el voto campesino de izquierda durante la Segunda República francesa y con la sublevación de 1851, que, según $\mathrm{E}$. Weber, no supuso que "la política" - tal como la entendemos en una sociedad contemporánea- hubiera llegado en 1849 a los campesinos, sino la persistencia de formas tradicionales de participación, basadas en lealtades o prestigios personales, mientras que otros, como T.W. Margadant, opinan que sí se produjo un cambio fundamental consecuencia de un proceso complejo en el que intervinieron muy distintos factores ${ }^{9}$.

El caso de Navarra donde, durante el período 1891-1923, resultaron elegidos cuarenta y un carlistas y siete integristas, de un total de ciento diecisiete diputados, es un buen ejemplo de lo anterior que, según María Cruz Mina, hay que interpretar como un fenómeno de continuidad de los antiguos procedimientos, más que de renovación de la vida política. A pesar de que el partido carlista - dice Mina- "contó con una organización en base a juntas locales y de merindad, y a una red de círculos o casinos. Y si no era propiamente un partido de masas, era un partido con masas relativamente fieles y disciplinadas (...) las prácticas electorales en Navarra en nada se diferenciaron de las otras provincias. Las compras de votos en dinero o en especie, las coacciones materiales sobre renteros amenazados con el deshaucio, o sobre feligreses amenazados con el de deshaucio eterno, fueron denuncias que no faltaron en ninguna elección": aparte del apoyo que los carlistas recibieron en determinados momentos de los gobiernos conservadores de Madrid, interesados en "contar con una minoría carlista e integrista en las Cortes que contrapesase los impulsos democratizadores de la izquierda" ${ }^{10}$.

\section{EL PROBLEMA DEL CACIQUISMO}

En el resto de mi intervención voy a ocuparme exclusivamente de algunos aspectos relativos al problema del caciquismo que, como ha que-

9 Weber, E., "The Second Republic. Politics and the Peasant", French Historical Studies 11 (1980), 521-550 y "Comment la politique vint aux Paysans": A second look at peasant politicization", American Historial Review 87 (1982), 357-389. MARgadANT, T. W., French Peasant in Revolt: The Insurrection of 1851. Princeton $1979 \mathrm{y}$ "Tradition and Modernity in Rural France during the Nineteenth Century", Journal of Modern History 56 (1984), 667-697.

10 Mina, M. C., "Elecciones y partidos en Navarra, 1891-1923", en Garcia Delgado, J. L. (ed.), La España de la Restauración. Política, economía, legislación y cultura. Madrid 1985, págs. 111-129. 
dado indicado, es el fenómeno más característico de la vida política española, durante el reinado de Alfonso XIII, una persistencia del pasado que predominó sobre el conjunto de cambios que tuvieron lugar en el país durante este período.

No conocemos bien, todavía, la realidad del caciquismo en España, su naturaleza y evolución a lo largo de los siglos xIX y xx. Por una parte, tenemos una serie de interpretaciones generales, que plantean los problemas básicos, a los que dan soluciones diferentes y, en ocasiones, opuestas; soluciones que resultan teóricamente convincentes, pero que necesitan ser comprobadas en ár.bitos espaciales y temporales concretos. Por otra, un número relativamente abundante de estudios locales que, a pesar de su carácter riguroso, de la información realmente útil que proporcionan sobre el funcionamiento del sistema político y, en ocasiones, sobre sus bases sociales, son, en la mayor parte de los casos, fundamentalmente descriptivos, sin una base teórica adecuada, que no se plantean y, por tanto, no dan solución a los problemas básicos de la realidad política.

Así, por ejemplo, en estos estudios locales, se enumeran con frecuencia los medios utilizados por los caciques para imponerse en sus respectivos ámbitos de acción, sin tener en cuenta que esos medios, en muchos casos, son excluyentes entre si y que expresan instrumentos de control y formas de vida política esencialmente diferentes. Así, se habla de falsificación de los resultados electorales, de la compra de votos, de la concesión de favores, o del ejercicio de coacciones, basados en el dominio de la máquina administrativa o de los medios de producción, y de la práctica de la violencia física, sin concretar en qué medida o extensión se utilizaban, por lo que no sabemos si nos encontramos ante el predominio de la apatía y la indiferencia del electorado - que permitía el fraude o la compra de votos--, ante sociedades clientelares de base política o económica, o ante una población políticamente movilizada que era sistemáticamente reprimida. Aplicamos el nombre de caciquismo a todas estas situaciones, que indudablemente se dieron, pero desconocemos su concreción geográfica y su evolución a lo largo del tiempo.

A continuación expondré lo que creo son las dos interpretaciones básicas del caciquismo, destacando sus principales elementos constitutivos, que los sucesivos estudios locales sobre el tema deberían tratar de comprobar en sus respectivas áreas, para que podamos llegar a saber en qué consistió realmente el caciquismo, cuándo y dónde.

Las dos interpretaciones generales, y opuestas, del caciquismo han sido expresadas quizá en su forma más clara y concisa por Richard Herr, por una parte, y Joaquín Romero Maura y José Varela Ortega, por otra. 
Ambas interpretaciones consideran el caciquismo como una forma de control social y político, de gran importancia durante todo el régimen liberal; según Herr era, sobre todo, una forma de dominación de clase, un tipo de relación creada por las elites tradicionales, económicamente poderosas, para mantener su posición privilegiada; por el contrario, para Romero Maura y Varela Ortega, se trata de una relación de clientelismo o patronazgo, de raíces políticas, y de la que se beneficiaron tanto las elites tradicionales como otras nuevas que surgieron, precisamente, a causa de las posibilidades creadas por la implantación del régimen liberal. En ambas interpretaciones cabe distinguir una distinta opinión sobre la base fundamental en que se asienta el caciquismo - económica o política-, y sobre la naturaleza de la relación en que consiste - coactiva o relativamente armoniosa- ${ }^{11}$.

\section{a) La base del caciquismo}

La interpretación del caciquismo como fenómeno de raíces económicas, tiene como antecedentes, entre otros, a Manuel Azaña y a Gerald Brenan. Azaña lo expresó de forma particularmente contundente: "La oligarquía como sistema, y el caciquismo como instrumento - exclusión de la voluntad de los más-, son anteriores al régimen, constitucional y al sufragio y han persisitido con ellos; la oligarquía fue nobiliaria y territorial; hoy es burguesa y, en su núcleo más recio y temible, capitalista, aborto de la gran industria y de la finanza (...) Es absurdo hablar del caciquismo como una consecuencia natural de la democracia, o del sistema parlamentario (...) Madrid no es el foco del caciquismo (...) El caciquismo viene de abajo arriba (...) El poder del cacique es anterior a cualquier constitución, a toda urdimbre política.» Por su parte, G. Brenan afirmaba que "lo más probable es que siempre haya habido caciques en España"; y que el modo particular de actuación de los caciques, "variaba de acuerdo con las características de la propiedad del suelo" ${ }^{12}$.

Richard Herr ofrece la exposición más sistemática de esta interpretación, en un artículo en el que analiza la respuesta de las elites rurales españolas a las distintas ofensivas modernizadoras del siglo XIX, en el

11 Herr, R., "Spain" en Spring, D. (ed.), European landed elites in the nineteenth century. Baltimore 1977, págs. 98-126. VARELA OrTEGA, J., Los amigos politicos. Partidos, elecciones y caciquismo en la Restauración (1875-1900). Madrid 1977, en especial, págs. 353-369.

12 AZAÑA, M., "Caciquismo y democracia", en Plumas y Palabras. Barcelona 1976, págs. 199203. Brenan, G., El Laberinto Español. Barcelona 1977, págs. 30-32. 
contexto europeo. El caciquismo es, según Herr, el procedimiento que dichas elites pusieron en práctica para conjurar la amenaza que para su preeminencia social suponía el gobierno parlamentario y el sufragio universal. En el siglo XVIII, según Herr, dichas elites resistieron desde sus enclaves locales las ofensivas racionalizadoras de la monarquía reformista; con el cambio de régimen comprendieron que estarian mucho más seguras si, en vez de tratar exclusivamente de resistir a su acción, llegaban a controlar el Estado. Y, gracias al caciquismo, lo consiguieron.

No tiene sentido, según Herr, establecer una conexión funcional entre el papel público que desempeñaba el cacique y su poder como tal; con frecuencia, los caciques formaban parte de las jerarquías política y administrativa, pero su poder no se derivaba de su pertenencia a las mismas, sino que era algo previo. Ante la debilidad del aparato del Estado, como consecuencia de la inestabilidad del régimen liberal a lo largo del siglo, sacudido por guerras civiles y revoluciones, las elites rurales crearon una organización específica para mantener el orden y para gobernar el país de acuerdo con sus intereses. El caciquismo sería, por tanto, una tercera jerarquía, paralela a la administrativa y a la política, creada por las elites rurales para mantener el país bajo su control. Era su pertenencia a esta tercera jerarquía lo que hacía poderosos a los caciques y no su esporádica aparición en las otras dos ${ }^{13}$.

El otro grupo de interpretaciones resaltan, por el contrario, la relativa independencia y novedad del sistema y las elites políticas, respecto de las estructuras económicas. Así, Romero Maura, después de rechazar las interpretaciones globales del caciquismo basadas en el control económico, la represión, el aislamiento geográfico, el atraso económico, y la psicología de los españoles, expone su interpretación en la que los elementos clave son la desmovilización general, la indiferencia hacia la política, de la mayor parte de la población, por una parte, y la apropiación por parte del cacique de los recursos políticos, por otra. El cacique, afirma, obtiene siempre su poder del ejercicio arbitrario e interesado de las funciones administrativas; es secundario el camino que haya utilizado para alcanzar la posición que ocupa, que sea o no el rico del pueblo, aunque si es el rico lo habrá tenido más fácil; lo esencial es que se mantiene en su posición repartiendo favores políticos, utilizando discriminatoriamente la Administración pública ${ }^{14}$.

\footnotetext{
${ }^{13}$ Herr, R., op. cit.

${ }^{14}$ La expresividad del siguiente párrafo de Joaquín Romero Maura, a pesar de su longitud, creo que justifica su reproducción: "En el proceso de formación de los primeros núcleos de clientela; en la lucha por monopolizar la representación local, comarcal o hasta regional, de
} 
En el mismo sentido, se ha expresado J. Varela Ortega: «Si se pretende establecer una correlación inmediata y necesaria (entre las formas de poder social y económico) con el sistema de poder político - dice-se corre el riesgo de perder la clave de éste. Asimismo, hay que evitar la tentación de establecer relaciones simples de causa y efecto entre la base social y económica de la clase política en cuestión y la fuente de poder político. El no hacerlo ha llevado a interpretaciones distorsionadas; la más popular de las cuales viene a entender el poder político de la Restauración como dependiente de una oligarquía terrateniente-financiera todopoderosa (...) Las organizaciones caciquiles podían servirse del poder económico (...) pero ello no era característica general y sistemática ni, sobre todo, condición necesaria (...) Como fuente de poder, ni el dinero ni la represión violenta eran generales, decisivos ni suficientes (...) Es claro que el control del mercado de trabajo generaba servidumbres y establecía vínculos, pero hay que guardarse de tomarlo por la clave del sistema. Ésta estaba en el control de la Administración" ${ }^{15}$.

Ambas interpretaciones, aunque plantean problemas que sus mismos autores reconocen, son teóricamente convincentes, en líneas generales Lo que necesitamos de los estudios locales, como ya he dicho, es que traten de verificarlas en sus respectivas áreas de estudio, analizando la composición y las bases del poder de las elites políticas, y su relación con las elites económicas. Los fundamentos económicos y políticos, por

uno de los partidos dinásticos; en la pugna por controlar los funcionarios locales a costa de la legalidad; en multitud de casos, el hombre fuerte o rico y con deudos tiene grandes ventajas. El terrateniente andaluz o extremeño, el comerciante de granos castellano, el abogado gallego con un buen bufete, notarios, médicos, propietarios de periódicos, banqueros, industriales fuertes, vinicultores, conocen a las gentes locales y tienen a menudo sobre ellos un ascendiente fundado en una posición de superioridad social relativa, pero muy tangible. Es muy difícil, imposible, separar del todo en estos casos la parte de influencia derivada de esa posición y la que genera la calidad del jefe local del partido. Pero es obvio que tales hombres tienen en sus distritos y áreas de influencia una fuerza de la que carecen otros hombres con tantos medios privados como ellos, pero con menos o ninguna vinculación con el aparato de los partidos. Por otra parte, creo que es conveniente volver a llamar la atención sobre el hecho de que no faltan en las fuentes ejemplos de caciques completamente desdinerados, trátese de gentes de raigambre más o menos noble, pero decaída, o de hombres de origen y condición decididamente plebeyos, que derivan toda su influencia de su posición de jefes locales del partido respectivo y que son políticamente tan poderosos como el cacique más fuerte. Puede que sean relativamente escasos: pero si bien eso mostraría quizá que para el hombre sin otros recursos que su habilidad, es más difícil encaramarse en la cúspide de la pirámide politica del lugar, el hecho mismo de que se den esos casos es revelador de la fuerza que puede llegar a corresponder a quien sólo tiene a su haber el ocupar esta posición. Recuérdese que Camo, verdadero procónsul de la provincia de Huesca, el más famoso de todos los caciques de este siglo, cuyo nombre sale siempre en el bestiario de la época, era un sencillo pastelero de la capital provinciana".

15 Varela Ortega, J. op. cit., págs. 364-368. 
otra parte, no son excluyentes, pero lo que necesitaríamos saber es en qué medida uno de ellos resultó predominante y cómo evolucionó su relación a lo largo del curso del sistema parlamentario y del cambio económico en España. Además ambas formas de influencia pueden alcanzar, en un mismo momento, a diferentes personas dentro de una comunidad; tanto Romero Maura como Varela Ortega han resaltado que sólo una minoría podía beneficiarse de la acción administrativa controlada por los caciques, mientras la mayor parte de la población permanecía pasiva e indiferente, y el primero de los autores citados dice que debemos resignarnos a no entender dicha pasividad. Una posible explicación de la misma sería la existencia de algún tipo de control económico sobre la mayoría de la población, compatible con una redes políticas en las que sólo unos pocos notables estarían integrados. Es decir, la coexistencia de los dos tipos de influencia.

\section{b) Naturaleza de la relación}

El problema que se plantea ahora es si las relaciones entre caciques y subordinados eran relaciones de clase o relaciones de clientelismo. Uno de los participantes en la información sobre "Oligarquía y Caciquismo", promovida por Joaquín Costa, en 1901, proponía como remedio "contra la asquerosa llaga del caciquismo" - decía - la extensión de una sociedad clientelar - «la institución consuetudinaria conocida con el nombre de "compadrazgo" en los pueblos de la baja Alpujarra»- considerando que el caciquismo no era en absoluto una relación de este tipo, sino simplemente algo opresivo y desvastador. Sin embargo, la descripción clásica del fenómeno, entre otros por Joaquín Costa, que acentúa la importancia de las relaciones personales en el funcionamiento del sistema político, la aplicación arbitraria de la ley en función de decisiones personales - «no había que preguntar si teníais razón, si la ley estaba de vuestra parte, para saber cómo se fallaría el pleito, cómo se resolvería el expediente: había que preguntar si le era indiferente al cacique, y por tanto se mantendría neutral, o si estaba con vosotros o contra vosotros»- dan pie para considerarlo asi ${ }^{16}$.

${ }^{16}$ Espinosa, S., en Costa, J., Oligarquia y caciquismo como la forma actual de gobierno en España. Urgencia y modo de cambiarla. Madrid 1902, págs. 228-229. El compadrazgo, según Espinosa, "se trata de asociaciones de familias cuyo núcleo es una persona dotada, por su posición y por su respetabilidad, de un cierto grado de poder, de entendimiento y de ascendiente que le permite constituirse en guia, consejero y protector de otros más débiles que él, admitidos a su comunión, y que se apellidan en esta relación "compadres" suyos". CoSTA, J., ldem, pág. 16. 
Julián Pitt-Rivers, en su clásica obra The people of the Sierra, en unos párrafos que han sido extraordinariamente influyentes en la consideración antropológica posterior de la relación patrón-cliente, describe la evolución del caciquismo en España desde una forma de patronazgo basada en la amistad, a otra en la que ésta es sólo aparente y trata de encubrir el ejercicio del poder, por parte de los poderosos, en su beneficio exclusivo ${ }^{17}$. A lo largo de la obra, Pitt-Rivers expone una interpretación general de la realidad social, junto con determinadas características estructurales, costumbres y valores sociales, en las que encaja esta conceptualización del caciquismo.

El estudio de las relaciones clientelares o de patronazgo se ha visto incentivado, desde finales de los años sesenta, por lo que Huntington ha llamado "revisionismo del concepto de modernización"; concretamente, por la comprobación de la falsedad de la tesis defendida por los primeros teóricos de la modernización y el desarrollo político, de que los factores característicos de tradición y modernidad eran opuestos y excluyentes entre sí; por el contrario, como demostraron numerosos análisis históricos, en determinadas sociedades, algunos factores considerados modernos no impulsaron de hecho su transformación global, o fueron un obstáculo para la misma, mientra que en otras sociedades ya modernizadas, persisten valores e instituciones tradicionales que contribuyeron decisivamente a su transformación, determinando en gran medida la forma en que se desarrolló su proceso de cambio; el clientelismo se ha considerado un ejemplo de ellas ${ }^{18}$.

\footnotetext{
17 "La amistad en una relación entre personas desiguales se convierte en el fundamento del sistema de patronazgo. El hombre rico emplea, asiste y protege al pobre que, a su vez, trabaja en favor de aquél, dándole estima y prestigio, protegiendo sus intereses procurando que no sea robado, advirtiéndole de las maquinaciones de los demás y poniéndose de su parte en las discusiones. La relación de "padrino" y "hombre de confianza" es una especie de amistad desiquilibrada en la cual el elemento de simpatía no está en absoluto excluido, aunque puede suceder que (...) la apariencia de amistad sea usada para ocultar un arreglo puramente venal, el uso por parte de un hombre rico de su dinero para alcanzar sus fines. Parece haber habido un cambio en la evolución del caciquismo - cuyo núcleo era el sistema de patronazgo- desde el primer tipo de patronazgo al segundo. En un primer período "cacique" parece no haber tenido más significado que el de una persona de prestigio local, y uno se encuentra a un joven en una novela de Juan Valera (Pepita Jiménez, 1873) que se enorgullece de que su padre sea el "cacique" del pueblo, mientras que, al final de su curso, llegó a ser un término de oprobio con el que se designaba al chantagista y corruptor, a quien empleaba al matón del pueblo ( $C$. Baroja, Pío, César o nada, 1922)". Pitt-Rivers, J., The people of the Sierra (1954). Chicago $1971,140-141$

${ }_{18}$ Huntington, S., "The change to change", Comparative Politics 3 (1971), 283-332. TIPPS, D. C. "Modernization Theory and the Comparative Study of Societies: A critical perspective", en Comparative Studies in Society and History 15 (1973), 199-226.
} 
Lo que define básicamente la relación patrón-cliente es el acuerdo directo y personal, con independencia de cualquier institución o ley, entre dos personas desiguales por status y situación económica, para el intercambio de diferentes tipos de recursos, recursos que suelen ser de importancia más crucial para el cliente que para el patrón. Otras características secundarias, son el carácter particularista, difuso y afectivo de la relación, el fuerte sentido de lealtad y solidaridad que suele acompañarla $y$, a pesar de su carácter voluntario, el hecho de que su duración, en principio, sea ilimitada, para toda la vida ${ }^{19}$.

En relación con las interpretaciones del caciquismo, a las que me he referido anteriormente, quienes defienden su base económica, están próximos a la opinión del citado participante en la encuesta del Ateneo de Madrid, mientras que quienes afirman que descansaba en el control político, definen explícitamente el caciquismo como una forma de patronazgo. Los primeros más bien no se plantean el problema de la naturaleza de la relación entre caciques y personas bajo su influencia; parece que, una vez establecido el principio de la dominación económica, es superfluo todo lo demás; la relación no puede ser otra que de control o subordinación absoluta. Para los segundos, por el contrario, el caciquismo era una, o más bien, diversas formas de patronazgo; de acuerdo con la intensidad del vínculo, J. Varela Ortega distingue entre "caciquismo tradicional y apoyo deferencial", "caciquismo transicional y apoyo por compensación concreta", "caciquismo violento, o apoyo por amenazas" y “(caciquismo) transaccional, o apoyo comprado» ${ }^{20}$.

Pienso que para comprender correctamente el fenómeno del caciquismo en España, sería útil tener en cuenta dos aspectos de la institución del patronazgo, destacados en la literatura teórica sobre el tema y no suficientemente recogidos en las interpretaciones sobre el mismo: 1) que la dominación económica no excluye alguna forma de relación patróncliente, y 2) el fuerte sentido conservador, "organicista", que frecuentemente acompaña al concepto. Con la primera observación quiero señalar que las relaciones de clase pueden verse superadas o sustituidas por relaciones clientelares; con la segunda, alertar sobre la posible idealización que se deriva de la utilización del concepto de patronazgo.

1) El patronazgo puede darse tanto en una relación de naturaleza política como económica. La vinculación entre patronazgo e interpretación

19 EInSEnstadt, S. N. y Roniger, L., Patrons, clientes and friends. Interpersonal relations and the structure of trust in society. Cambridge 1984, págs. 48-49.

20 Varela Ortega, J., op. cit., págs. 360-361. 
política del caciquismo, no es, por tanto, conceptualmente necesaria. Es de gran utilidad la consideración, expuesta por Carl $H$. Landé, de la relación patrón-cliente como addenda, como algo añadido a cualquier otro tipo de relación previamente existente. Habitualmente, el patronazgo no surge en el vacío, sino que se añade a otra relación institucional ya establecida, para reforzarla o dotarla de nuevas características, institución que puede ser de cualquier tipo de naturaleza social, económica o políti$\mathrm{ca}^{21}$.

Se ha señalado, y es el núcleo de la interpretación política del caciquismo, que entre cualquier cargo político electivo -diputado, alcaldey sus votantes puede darse una relación de patronazgo, en la que los votos son cambiados por favores, a través del control de la máquina administrativa. Pero también puede darse esta relación de patronazgo, por ejemplo, entre el propietario de la tierra y el arrendatario o trabajador agrícola, entre el prestamista y su deudor, entre el propietario del ganado y los encargados de su explotación, etc., tratando de conseguir, por parte del patrón - el propietario, el prestamista- el reconocimiento de una superioridad o excelencia más allá de su poder económico, y por parte del cliente -arrendatario, trabajador agrícola, deudor - un trato de favor en la relación económica establecida. Entre ambos se establece entonces un conjunto de obligaciones mutuas que va más allá de su pura relación económica. Este patronazgo de base económica puede tener también una proyección política si, con ocasión de cualquier convocatoria electoral, por ejemplo, el patrón trata de aprovechar en favor propio o de sus partidarios la adhesión de su clientela. $Y$ este voto no se produce tanto por la presión o coacción del hombre rico y poderoso sobre su subordinados, sino por la correspondencia de éstos a otro tipo de prestaciones que reciben de aquél. El resultado es el mismo, pero la explicación, la naturaleza de la relación, es diferente. Esta es, al menos, una situación posible $y$ que es necesario tener en cuenta ${ }^{22}$.

${ }^{21}$ LANDÉ, C. H., "The dyadic basis of clientelism", introducción a SchmitT, S. et alii (eds.), Friends, Followers and Factions. Berkeley, CA, 1977, págs. XII-XXXIII.

${ }^{22}$ Como punto de referencia, puede señalarse la explicación dada por Frank O'Gorman de los resultados electorales en Inglaterra, en el período inmediatamente anterior a la reforma de 1832. Oponiéndose a lo que denomina "una de las más poderosas ortodoxias de la historiografia británica moderna", la consideración del electorado como esencialmente pasivo, controlado por el poder económico, siguiendo a los propietarios "como ovejas al pastor", O'Gorman expone, y trata de probar, un comportamiento en el que resulta determinante la deferencia que se deriva del patronazgo ejercido por los poderosos. O'Gorman, F., "Electoral Deference in "Unreformed" England, 1760-1832", en Journal of Modern History 56 (septiembre de 1984), 391429. 
Por tanto, la naturaleza de la relación entre caciques y subordinados puede ser de clase o de patronazgo, con independencia de la base sobre la que se asiente. Nuevamente son los análisis locales los que tienen que corroborar una u otra tesis, que dada su naturaleza subjetiva, son de un conocimiento mucho más dificultoso.

2) El segundo aspecto, resaltado en la literatura sobre el patronazgo al que me he referido, es el sentido conservador que acompaña al concepto. Como ha escrito R. Lemarchand, unacido y alimentado en el terreno conservador de la antropología estructural, el concepto de clientelismo lleva consigo el estigma de lo que podría verse como un predectible defecto de nacimiento: su fuerte inclinación conservadora, reminiscente de conceptos sociales "organicistas". La visión de la sociedad que conlleva es la de un sistema altamente cohesivo e integrado, en el cual hay una interdependencia relativamente armoniosa entre las partes que lo com. ponen» ${ }^{23}$.

Una utilización acrítica de esta noción puede distorsionar completamente la realidad social, al excluir de ella todo elemento de conflicto. E patronazgo es una forma de control social que, en muchas ocasiones, puede ocultar de hecho formas coactivas de dependencia. El criterio básico para saber si en realidad estamos ante una forma de patronazgo es comprobar si se da de hecho el intercambio de recursos, el beneficio de las dos partes que componen la relación, dentro de unos determinados límites estructurales.

Los aspectos señalados no agotan, en absoluto, la realidad múltiple y compleja del caciquismo. Han quedado fuera de nuestra consideración, entre otros, el problema de las relaciones entre elites locales y poder central, que plantearon Temime y Chastagneret ${ }^{24}$; la sustitución del patronazgo individual por otro colectivo, de sindicatos o partidos; la virtualidad del sistema de clientelas para favorecer el desarrollo político; o las condiciones que explican la disolución de las relaciones clientelares. Sirva lo tratado como ejemplo de la necesidad de mejorar nuestro conocimiento del caciquismo en España, mediante una serie de estudios locales que, con la suficiente base teórica, traten de explicar la realidad del compor-

${ }^{23}$ Lemarchand, R., "Comparative Political Clientelism: Structure, Process and Optic", en El. Senstadt, S. N. y Lemarchand, R. (eds.), Political Cliente/ism, Patronage and Development. Londres 1981.

${ }^{24}$ Temine, E. y Chastagneret, J., "Contribution à l'etude des sources et des formes des pouvoirs locaux dans l'Espagne rurale contemporaine. Reflexions sur le caciquisme", en Cahiers de la Mediterranée. Actes des journées d'etudes Bedor, 26-28 de abril de 1978. 
tamiento político y electoral, y no sólo de describir los aspectos más superficiales del mismo.

\section{BIBLIOGRAFÍA SELECCIONADA}

\section{Sobre España}

ARtolA, M., Partidos y programas políticos, 1808-1936. Madrid 1974, 2 vols.

Ben-AmI, Sh., Fascisme from above. The Dictatorship of Primo de Rivera in Spain, 1923-1930. Oxford 1983

CARR, R., Spain, 1808-1975. Oxford 1982, 2. ${ }^{\mathrm{a}} \mathrm{ed}$.

DARDÉ, C., "La implantación de la democracia en la España de la Restauración", Revista de Occidente 50 (junio de 1985), 115-126.

García Delgado, J. L.; Sánchez Jiménez, J. y Tuñón de Lara, M., Los comienzos del siglo xx. La población. La economia. La sociedad, 1898-1931. Madrid 1984.

HERR, R., "Spain" en SPRING, D. (ed.), European landed elites in the nineteenth century. Baltimore 1977.

KERN, R. (ed.), The caciques. Oligarchical politics and the system of caciquismo in the LusoHispanic World. Alburquerque 1963.

LINZ, J., "Parties, elections and elites under the Restoration monarchy in Spain, 1875-1923", Association Seventh World Congress International Political Science. Bruselas, 18th-23th, 1967.

- " «The Party System of Spain. Past and Future", en LIPSET, S. M. y Rokkan, S. (eds.), Party system and voter alignements. Nueva York 1967.

Malefakis, E., Agrarian Reform and Peasant Revolution in Spain. New Haven 1970.

Martínez Cuadrado, M., Elecciones y partidos políticos de España, 1868-1931. Madrid 1969, vol. II.

RANZATO, G., "Natura e funzionamento di un sistema pseudorappresentativo: La Spagna "liberaldemocratica, 1875-1923'", en Suffagio, rappresentanza, interessi. Istituzioni e società fra '800 e '900. Angeli, Annali della Fondazione Lelio e Lisli Basso-Issoco. Angeli 1989.

Richard, B., "Etudes sur les gouverneurs civils en Espagne de la Restauration à la dictature 1874-1923", en Mélanges de la Casa de Velázquez. Madrid 1972.

RIQUER, B. de, "La sociología electoral de la monarquía y de la Segunda República española", en Simposio: Desarrollo regional, nacionalismos y regionalismos en España. Bad Homburg. 26-28 de junio de 1980.

Romero Maura, J., "El caciquismo", en Andrés-Gallego, J. (coord.), Revolución y Restauración, 1868-1931. Madrid 1981

Temime, E. y Chastagneret, J., «Contribution à l'etude des sources el des formes des pouvoirs locaux dans l'Espagne rurale contemporaine. Reflexions sur le caciquisme", en Cahiers de la Mediterranée. Actes des journées d'etudes Bedor, 26-28 de abril de 1978.

TUSELL, J., "Para la sociología política de la España contemporánea: El impacto de la Ley de 1907 en el comportamiento electoral", Hispania XXX, 116 (1970), 571-631.

Varela Ortega, J., Los amigos políticos. Partidos, elecciones y caciquismo en la Restauración, 1875-1900. Madrid 1977.

\section{Por Comunidades Autónomas}

ANDALUCIÁA

PItT-Rivers, J., The people of the Sierra (1954). Chicago 1971.

Rulz Pérez, Rafael y Rulz Pérez, Ricardo, Propiedad de la tierra y caciquismo. (El caso de Dolar en tiempos de Altonso Xill.). Granada 1987. 
TUSELL, J., Oligarquía y caciquismo en Andalucía, 1890-1923. Barcelona 1976.

- , "El sistema caciquil andaluz comparado con otras regiones españolas", Revista Española de Investigaciones Sociológicas (1978), 7-19.

ARAGÓN

Frias Corredor, C. y Trisán Casals, M., El caciquismo altoaragonés durante la Restauración. Huesca 1987.

ASTURIAS

Gırón, J., “Elecciones municipales y generales, 1902-1917», en Historia General de Asturias, vol. 5, págs. 161-176.

GonzÁlez Muñiz, M. A., “Elecciones en el período 1918-1923», en Historia General de Asturias, vol. 6, págs. 49-64.

CANARIAS

Norena Salto, M. T., Canarias: Política y sociedad durante la Restauración. Santa Cruz de Tenerife 1977, 2 vols.

CANTABRIA

Garrido Martín, A., Elecciones y partidos políticos en Cantabria, Memoria de Licenciatura inédita. Universidad de Cantabria, 1986.

\section{CASTILLA-LEÓN}

Caballero Dominguez, M., Las elecciones municipales en Soria capital entre 1874 y 1923 , tesis de licenciatura. Universidad de Zaragoza, 1980.

Romero, C., Soria, 1868-1936 (Aspectos demográficos, socioeconómicos, culturales y políticos). Soria 1981.

CASTILLA-LA MANCHA

BarReda Fontes, J. M., Caciques y electores. Ciudad Real durante la Restauración, 1876-1923. Cludad Real 1986.

Casa Navarro, F., La vida política toledana durante el reinado de Alfonso XIII, 1902-1931, tesis doctoral presentada en la UNED, 1986.

TUSELL, J., "Una elección en la época caciquil: Guadalajara, 1907". Revista Española de Investigaciones Sociológicas 6 (1979), 53-83.

EXTREMADURA

Merinero, M. J., Comportamiento politico en Cáceres, 1891-1931. Cáceres 1980. 
GALICIA

Barreiro Fernandez, M. R., Historia de Galicia. Vigo 1981.

DURÁn, J. A., Agrarismo y movilización campesina en el País Gallego, 1875-1912. Madrid 1977 TABOADA MOURE, P., Las elites y el poder político. Elecciones provinciales en Pontevedra, 18361923. Pontevedra 1987

MADRID

TUSELL, J., Sociologia electoral de Madrid, 1903-1931. Madrid 1969

- "El comportamiento electoral madrileño revisitado", en BAHAMONDE MAGRo, A. y Otero CaRvaJAL, L. E. (eds.), La sociedad madrileña durante la Restauración. Madrid 1989, vol. Il.

NAVARRA

Mina, M. C., “Elecciones y partidos en Navarra, 1891-1923», en Garcia Delgado, J. L. (ed.), La España de la Restauración. Política, economia, legislación y cultura. Madrid 1985.

PAIS VASCO

CAStells, L., Modernización y dinámica política en la sociedad guipuzcoana de la Restauración. 1876-1915. Madrid 1987.

Cillan Apalategui, A., Sociología electoral de Guipúzcoa, 1900-1936. San Sebastián 1975.

Fusi, J. P., Politica obrera en el Pais Vasco, 1880-1923. Madrid 1975.

Sobre problemas de modernización y cambio politico

Clapham, C., "Clientelism and the State", en Clapham, C. (ed.), Private Patronage and the State. Londres 1982.

EIsenstadt, S. N. y Roniger, L., Patrons, clientes and friends. Interpersonal relations and the structure of trust in society. Cambridge 1984

O'Gorman, F., "Electoral Deference in "Unreformed" England, 1760-1832", en Journal of Modern History 56 (septiembre de 1984), 391-429.

HELD, D., Models of Democracy. Cambridge 1987.

Huntington, S., Political Order in Changing Societies. New Haven 1968

- , "The change to change", Comparative Politics 3 (1971), 283-332.

KENNY, M., "Patterns of patronage in Spain" (1960), en SCHMIDT, S. et alii (eds.), Friends, Followers and Factions. Berkeley, CA, 1977.

LANDÉ, C. H., "The Dyadic Basis of Clientelism", introducción a SCHMIDT, S. et alii (eds.), op. cit. LemarChand, R. y LEGG, K., "Political Clientelism and Development", Comparative Politics 4,2 (1972), 149-178.

Lemarchand, R., "Comparative Political Clientelism: Structure, Process and Optic", en Eisenstadt, S. N. y Lemarchand, R. (eds.), Political Clientelism, Patronage and Developement. Londres 1981.

LEYS, C., "Samuel Huntington and the end of classical modernization theory", en ALAVI, H. y SHANIN, T., Introduction to the Sociology of "Developing Societies". Londres 1982.

MARGADANT, T. W., "Tradition and Modernity in Rural France during the Nineteenth Century", Journal of Modern History 56 (1984), 667-697. 
Randall, V. y Theobald, R., Political Change and Underdevelopment. A Critical Introduction to Third World Politics. Londres 1985.

Riggs, F. W., "Bureaucrats and Political Development: A Paradoxical View", en LAPALOMbara, J. (ed.), Bureacracy and Political Development. Princeton 1963.

ROKKAN, S., "The comparative study of political participation. Notes toward a perspective on current research", en RANNEY, A. (ed.), Essays on the behavioral study of politics. Urbana 1962.

TheObald, R., "The decline of Patron-Client Relations in Developed Societies", Archives Européennes de Sociologie XXIV (1983), 136-147.

TIPPS, D. C., "Modernization Theory and the Comparative Study of Societies: A critical perspective", en Comparative Studies in Society and History 15 (1973), 199-226.

WEBER, E., "The Second Republic. Politics and the Peasant", French Historical Studies 11 (1980), 521-550.

-, "Comment la politique vin at aux Paysans": A second look at peasant politicization", American Historical Review 87 (1982), 357-389.

Weingrod, A., "Patrons, Patronage and Political Parties", Comparative Studies in Society and History $10(1968), 377-400$ 